\title{
Plasma-rich fibrin in neurosurgery: a feasibility study
}

\author{
Tom Theys $^{1}$ (D) Anais Van Hoylandt ${ }^{1} \cdot$ Charlotte-Elise Broeckx $^{1} \cdot$ Laura Van Gerven ${ }^{2} \cdot$ Joyce Jonkergouw $^{3}$. \\ Marc Quirynen ${ }^{4}$. Johannes van Loon ${ }^{1}$
}

Received: 28 February 2018 / Accepted: 30 May 2018 / Published online: 6 June 2018

(C) Springer-Verlag GmbH Austria, part of Springer Nature 2018

\begin{abstract}
Background Cerebrospinal fluid (CSF) leakage represents an important and sometimes challenging complication in both cranial and spinal surgery. Current available options for dural closure pose inherent problems regarding safety, efficacy, immunogenicity, cost, and invasiveness. In this article, the use of leukocyte- and platelet-rich fibrin (L-PRF) derived from the patient's own blood is proposed to facilitate dural closure. We aim to describe the safety, feasibility, and applicability of L-PRF membranes and plugs in cranial and spinal neurosurgery.

Methods A retrospective study reviewing clinical and surgical characteristics was conducted in 47 patients in whom the use of LPRF was attempted to reinforce dural closure at a single institution during 1 year. Procedures included skull base, posterior fossa, and spinal revision surgeries.

Results L-PRF membranes and/or plugs were used in 44 surgeries. The preparation of L-PRF failed in three cases. L-PRF membranes were used as onlay grafts to augment sealing or sutured into a defect. No short-term complications related to the use of L-PRF were recorded. Postoperative CSF leakage was present in two endoscopic transsphenoidal pituitary surgeries and in one spinal CSF leak repair.

Conclusion L-PRF is safe, inexpensive, and completely autologous and can be rapidly and non-invasively harvested to aid in dural closure. Theoretical advantages include a regenerative bioactive potential, which could lead to improved wound healing and reduced infection rates. These findings warrant larger prospective studies to determine the potential role of L-PRF in neurosurgery.
\end{abstract}

Keywords L-PRF $\cdot$ Dural closure $\cdot$ Skull base $\cdot$ CSF leak $\cdot$ Regenerative medicine

\section{Introduction}

Watertight dural closure has been a challenge since the birth of neurosurgery in the late nineteenth century when thin gold foil

This article is part of the Topical Collection on Neurosurgery general

Tom Theys is a Senior Clinical Investigator of FWO Flanders (FWO $1830717 \mathrm{~N})$.

Tom Theys

tom.theys@uzleuven.be

1 Department of Neurosurgery, University Hospitals Leuven, 3000 Leuven, Belgium

2 Department of Otorhinolaryngology, University Hospitals Leuven, Leuven, Belgium

3 Department of Maxillofacial surgery, University Hospitals Leuven, Leuven, Belgium

4 Department of Periodontology \& Oral Microbiology, University Hospitals Leuven, Leuven, Belgium leafs and rubber were used for dural sealing [5]. In the twentieth century, different autogenic, allogenic, xenogenic, and synthetic grafts have been introduced as a dural substitute, all with their specific advantages and disadvantages.

Although the documented use of fibrin as a hemostatic agent in brain surgery dates back to 1915 [17], the first clinical use of fibrinogen in combination with thrombin as a sealant was reported during World War II to enhance skin grafting [9]. Since this preliminary report, the performance of fibrin sealants has made substantial improvements with respect to clotting time, tensile strength, and adhesive properties. The use of fibrin-based sealants has become mainstream in many surgical fields $[3,10,13,18,22,26,27,29$, $31]$, due to the role of fibrin in hemostasis and wound healing. In neurosurgery, fibrin sealants are currently applied for their hemostatic, sealant, and adhesive properties [28]. Commercial fibrin glues, although proven very helpful, have specific downsides related to immunogenicity (including anaphylactic shock), production costs, storage, and mechanical strength. 
Leukocyte- and platelet-rich fibrin (L-PRF) comprises a high-density fibrin clot, an autologous matrix mesh with a high concentrate of platelets and leukocytes resulting from the coagulation cascade initiated in sterile blood collection tubes.

L-PRF is currently widely used in the field of oral and maxillofacial surgery, and indications are expanding to other specialties as well $[2,6,7,11,20,24,25]$. L-PRF can be applied in the form of a plug or a membrane and can even be sutured to mucosal surfaces [1].

Since autologous blood is readily available at a very low cost, we have initiated a study on the feasibility and applicability of the use of L-PRF for neurosurgical procedures, with a main focus on skull base surgery where the risk of CSF leakage is higher and dural reconstruction more arduous.

While a recent study reported on bone defect reconstruction and postoperative healing in skull base surgery $[16,30]$, the current study reports on the feasibility and safety of the use of L-PRF to obtain dural closure in cranial and spinal neurosurgery. Surgical strategies, technical issues, and theoretical advantages are discussed.

\section{Methods}

\section{Study design and preoperative evaluations}

From a prospectively compiled database including adult patients (age $\geq 18$ years), we retrospectively studied all consecutive neurosurgical procedures with the use of L-PRF performed at the University Hospitals Leuven during a 1-year period from February 2017 to January 2018. Procedures included cranial and spinal surgeries with a relatively higher propensity for CSF leakage: skull base surgery, posterior fossa surgery, and spinal revision cases for chronic CSF leak. Ethical approval for this study was obtained from the local ethical committee.

\section{L-PRF preparation}

The following protocol was used in all cases. The patient's own blood was obtained by the anesthesiologist via a $20-\mathrm{ml}$ syringe. Since an arterial line was present in most cases (in particular cranial procedures), arterial blood was often used. In the remaining cases, blood was obtained via venipuncture, e.g., in spinal cases. Depending on the anticipated number of L-PRF clots used $(2,4,6$, or 8$)$, a variable number of IntraSpin ${ }^{\mathrm{TM}}$ blood collection tubes were filled with $9 \mathrm{ml}$ of autologous blood, after which the tubes were immediately centrifuged at $2700 \mathrm{rpm}$ for $12 \mathrm{~min}$ in the IntraSpin ${ }^{\mathrm{TM}}$ Centrifuge (at room temperature) to separate the blood into different segmented components [12] (Fig. 1a). Fibrin clots were removed in a sterile fashion with the use of forceps and separated from the blood clot (Fig. 1b). Serum was expressed with the use of the weighted press (Xpression ${ }^{\mathrm{TM}}$ Box) of which the mechanical forces by gravity create consistent 1mm thick L-PRF membranes (Fig. 1b). L-PRF plugs (Fig. 1b) were made with the use of the piston and cylinder assembly (Xpression $^{\mathrm{TM}}$ Box).

\section{Surgical data and postoperative complications}

Surgical reports on all procedures were carefully analyzed with regard to the surgical approach and technique, as well as perioperative complications. Postoperative complications in particular surgical site infection, treatment-site bleeding, and CSF leakage were meticulously recorded.

\section{Results}

\section{Patient characteristics}

A prospectively collected database since February 2017 recorded 47 patients (Table 1) in whom the use of L-PRF was attempted. A total of 44 surgeries were performed with the use
Fig. 1 L-PRF preparation. a Venous or arterial blood was collected with a syringe, injected into glass blood collection tubes, and immediately centrifuged $(<$ $60 \mathrm{~s}$ ) without anticoagulant. b Separation of the resulting fibrin clot (sometimes called snot clot) from acellular plasma and red blood cells. c L-PRF can be transformed into membranes or plugs via slow compression
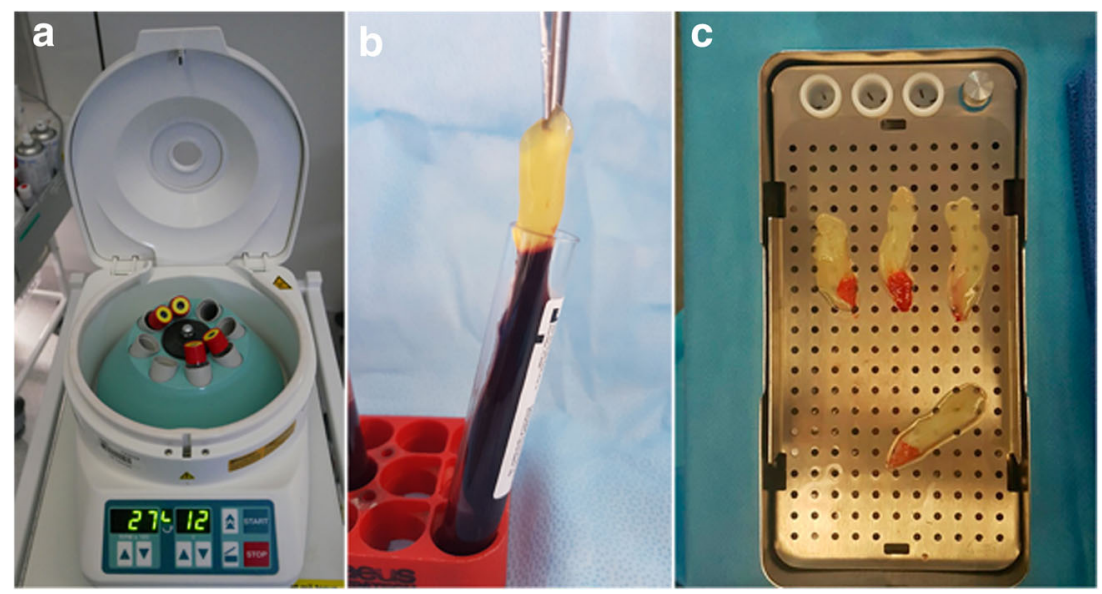
Table 1 Overview of patient characteristics, surgical procedure, and follow-up

\begin{tabular}{|c|c|c|c|c|c|c|}
\hline Patient & Sex & Age & Procedure & L-PRF preparation & Follow-up (weeks) & CSF leak \\
\hline 1 & $\mathrm{~m}$ & 52 & MVD & Failed procedure & & \\
\hline 2 & $\mathrm{~m}$ & 70 & MVD & $4 \mathrm{M}$ & 37 & No \\
\hline 3 & $\mathrm{f}$ & 40 & MVD & Failed procedure & & \\
\hline 4 & $\mathrm{f}$ & 46 & MVD & $4 \mathrm{M}$ & 18 & No \\
\hline 5 & $\mathrm{f}$ & 46 & MVD & $4 \mathrm{M}$ & 29 & No \\
\hline 6 & $\mathrm{~m}$ & 48 & MVD & $4 \mathrm{M}$ & 31 & No \\
\hline 7 & $\mathrm{f}$ & 34 & MVD & $4 \mathrm{M}$ & 7 & No \\
\hline 8 & $\mathrm{f}$ & 59 & MVD & $4 \mathrm{M}$ & 8 & No \\
\hline 9 & $\mathrm{f}$ & 63 & MVD & $4 \mathrm{M}$ & 10 & No \\
\hline 10 & $\mathrm{f}$ & 72 & PTM & $4 \mathrm{M}$ & 14 & No \\
\hline 11 & $\mathrm{~m}$ & 39 & ETS & $1 \mathrm{P}-3 \mathrm{M}$ & 28 & No \\
\hline 12 & $\mathrm{~m}$ & 51 & ETS & $1 \mathrm{P}-3 \mathrm{M}$ & 16 & No \\
\hline 13 & $\mathrm{f}$ & 84 & ETS & $1 \mathrm{P}-3 \mathrm{P}$ & 43 & No \\
\hline 14 & $\mathrm{f}$ & 60 & ETS & $1 \mathrm{P}-3 \mathrm{M}$ & 14 & No \\
\hline 15 & $\mathrm{f}$ & 49 & ETS & $1 \mathrm{P}-3 \mathrm{M}$ & 12 & No \\
\hline 16 & $\mathrm{f}$ & 83 & ETS & $1 \mathrm{P}-3 \mathrm{M}$ & 20 & No \\
\hline 17 & $\mathrm{~m}$ & 67 & ETS & $1 \mathrm{P}-3 \mathrm{M}$ & 29 & No \\
\hline 18 & $\mathrm{~m}$ & 63 & ETS & $1 \mathrm{P}-3 \mathrm{M}$ & 32 & No \\
\hline 19 & $\mathrm{~m}$ & 53 & ETS & $1 \mathrm{P}-3 \mathrm{M}$ & 5 & No \\
\hline 20 & $\mathrm{~m}$ & 67 & ETS & Failed procedure & & \\
\hline 21 & $\mathrm{f}$ & 37 & ETS & $1 \mathrm{P}-3 \mathrm{M}$ & 35 & No \\
\hline 22 & $\mathrm{~m}$ & 49 & ETS & $1 \mathrm{P}-3 \mathrm{M}$ & 14 & No \\
\hline 23 & $\mathrm{f}$ & 49 & ETS & $1 \mathrm{P}-3 \mathrm{M}$ & 24 & No \\
\hline 24 & $\mathrm{~m}$ & 25 & ETS & $1 \mathrm{P}-3 \mathrm{M}$ & 18 & No \\
\hline 25 & $\mathrm{f}$ & 36 & ETS & $1 \mathrm{P}-3 \mathrm{M}$ & 15 & No \\
\hline 26 & $\mathrm{~m}$ & 46 & ETS & $1 \mathrm{P}-3 \mathrm{M}$ & 8 & No \\
\hline 27 & $\mathrm{f}$ & 41 & ETS & $1 \mathrm{P}-3 \mathrm{M}$ & 8 & No \\
\hline 28 & $\mathrm{~m}$ & 27 & ETS & $1 \mathrm{P}-3 \mathrm{M}$ & 13 & No \\
\hline 29 & $\mathrm{~m}$ & 20 & ETS & $1 \mathrm{P}-3 \mathrm{M}$ & 5 & No \\
\hline 30 & $\mathrm{~m}$ & 32 & ETS & $1 \mathrm{P}-3 \mathrm{M}$ & 10 & No \\
\hline 31 & $\mathrm{~m}$ & 31 & ETS & $1 \mathrm{P}-3 \mathrm{M}$ & 11 & No \\
\hline 32 & $\mathrm{f}$ & 43 & ETS & $1 \mathrm{P}-3 \mathrm{M}$ & 6 & Yes \\
\hline 33 & $\mathrm{f}$ & 31 & ETS & $1 \mathrm{P}-3 \mathrm{M}$ & 3 & No \\
\hline 34 & $\mathrm{~m}$ & 59 & ETS & $1 \mathrm{P}-3 \mathrm{M}$ & 13 & No \\
\hline 35 & $\mathrm{f}$ & 60 & ETS & $1 \mathrm{P}-3 \mathrm{M}$ & 9 & No \\
\hline 36 & $\mathrm{~m}$ & 51 & ETS & $1 \mathrm{P}-3 \mathrm{M}$ & 9 & No \\
\hline 37 & $\mathrm{f}$ & 65 & ETS & $1 \mathrm{P}-3 \mathrm{M}$ & 3 & Yes \\
\hline 38 & $\mathrm{f}$ & 85 & ETS & $1 \mathrm{P}-3 \mathrm{M}$ & 3 & No \\
\hline 39 & $\mathrm{f}$ & 35 & ETS & $1 \mathrm{P}-3 \mathrm{M}$ & 7 & No \\
\hline 40 & $\mathrm{f}$ & 45 & ETS & $1 \mathrm{P}-3 \mathrm{M}$ & 6 & No \\
\hline 41 & $\mathrm{f}$ & 59 & ETS & $1 \mathrm{P}-3 \mathrm{M}$ & 5 & No \\
\hline 42 & $\mathrm{~m}$ & 71 & ETS & $1 \mathrm{P}-3 \mathrm{M}$ & 4 & No \\
\hline 43 & $\mathrm{v}$ & 64 & ETS & $4 \mathrm{C}$ & 4 & Yes \\
\hline 44 & $\mathrm{~m}$ & 51 & ETS & $4 \mathrm{C}$ & 4 & No \\
\hline 45 & $\mathrm{~m}$ & 67 & $\mathrm{CS}$ & $4 \mathrm{M}$ & 14 & No \\
\hline 46 & $\mathrm{f}$ & 63 & $\mathrm{~S}$ & $8 \mathrm{M}$ & 7 & No \\
\hline 47 & $\mathrm{~m}$ & 69 & $\mathrm{~S}$ & $8 \mathrm{M}$ & 6 & No \\
\hline
\end{tabular}

MVD microvascular decompression, PTM petrotentorial meningioma, ETS endoscopic transsphenoidal surgery, $C S$ craniotomy to sellar region, $S$ spinal repair, $P$ L-PRF plug, $M$ L-PRF membrane, $C$ L-PRF clot 


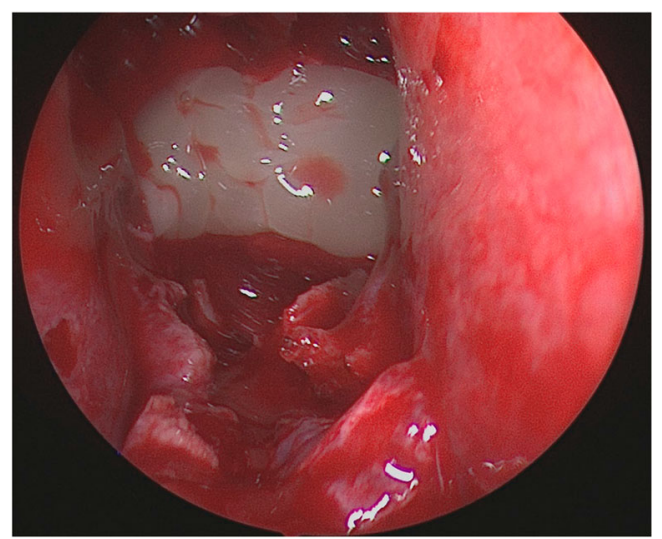

Fig. 2 L-PRF in transsphenoidal endoscopic surgery. L-PRF clots, plugs, and/or membranes can be applied to fill and cover a skull base defect

of L-PRF since the preparation of L-PRF failed in three cases $(6 \%)$. The median age at surgery was 51 years (range 20 85 years). Twenty-five patients (53\%) were female. Average follow-up was 3 months (range 3-43 weeks).

Indications for surgery included 34 endoscopic transsphenoidal surgeries, 9 microvascular decompressions (MVD), 2 skull base surgeries (petrotentorial meningioma $(N=1)$, transcranial approach to the sellar region $(\mathrm{N}=1))$, and 2 spinal dural repairs.

Four or eight L-PRF clots were used in all cases, either as a clot, a plug, or a membrane. Patient characteristics and surgery-specific factors are summarized in Table 1.

\section{Treatment: cranial applications}

\section{L-PRF in endoscopic transsphenoidal surgery}

In 29 patients (85\%) a macroadenoma was present, including 1 cystic macroadenoma and 1 surgery for a recurrence; 4 patients had a secreting microadenoma. A Rathke's pouch cyst was present in one case. In all endoscopic transsphenoidal surgeries $(N=34)$, four L-PRF constructs were used. In two cases, LPRF clots were directly applied without prior compression. In 32 cases, 1 L-PRF plug was inserted to fill the defect, while the other 3 membranes were used to cover the defect (Fig. 2). In 26 patients, a commercial liquid fibrin sealant (Tisseel®) was

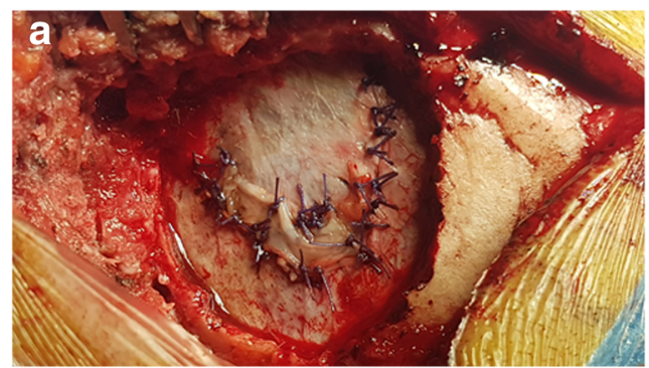

Fig. 3 L-PRF in posterior fossa surgery: microvascular decompression. a L-PRF membranes can be sutured into place without the need for different autologous tissues or artificial dura. $\mathbf{b}$ The adhesive properties additionally used, and in 8 patients, L-PRF was applied without other fibrin sealants. Intraoperative CSF leakage was observed in two cases $(6 \%)$. Postoperative CSF leakage was present in two other patients. No other postoperative complications were present.

\section{L-PRF in craniotomy}

Out of ten patients who had posterior fossa surgery, nine underwent MVD and one had a petrotentorial meningioma. One patient underwent supratentorial skull base surgery via a subfrontal approach to the sellar region. For craniotomy closure, L-PRF was used as a membrane that served as an autologous graft either sutured into place or as an onlay graft to reinforce dural reconstruction (Fig. 3a, b). Additional commercial sealant was used in all MVD cases to facilitate the application of the Teflon patch removing the offending vessel, and to put back craniectomy bone fragments. Commercial fibrin sealant was not used in the two other cases.

All craniotomies had an uneventful peri- and postoperative course, and no surgery-related complications, in particular CSF leakage nor treatment-site bleeding, were recorded.

\section{L-PRF in spine surgery}

Dural repair in spine surgery was performed in two patients with chronic postoperative CSF leaks, who were referred to our center after multiple surgeries to attempt dural repair. Both cases involved chronic CSF leaks with symptoms of intracranial hypotension and lumbar subcutaneous swelling. Preoperative MRimaging revealed an impressive lumbar pseudomeningocele in both patients. Both patients had already undergone three revision surgeries for dural repair with the use of collagen biomatrix (Tissudura ${ }^{\circledR}$ ) and dural sealant (Tisseel $®$ ), muscle/fascia graft, external lumbar drainage, and repetitive blood patches.

Eight L-PRF membranes were used for dural closure. In one case, a 3-cm large defect was present and L-PRF was sutured into the dural gap (Fig. 4a), whereas in the other case, L-PRF membranes were used as onlay grafts to reinforce dural closure (Fig. 4b). A Tachosil® collagen sponge was added to the L-PRF membranes.

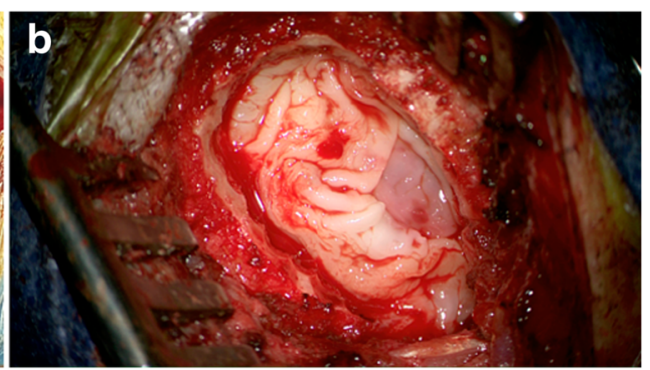

of L-PRF can serve to cover and reinforce the dural suture line or to close small dural defects without suturing the membrane in place 
Fig. 4 L-PRF in spinal surgery: postoperative chronic CSF leak. a Attempt to close a large spinal dural defect $(3 \times 3 \mathrm{~cm})$ with the use of a double layer of L-PRF membranes. b Several L-PRF membranes were used as onlay grafts to cover the spinal dura
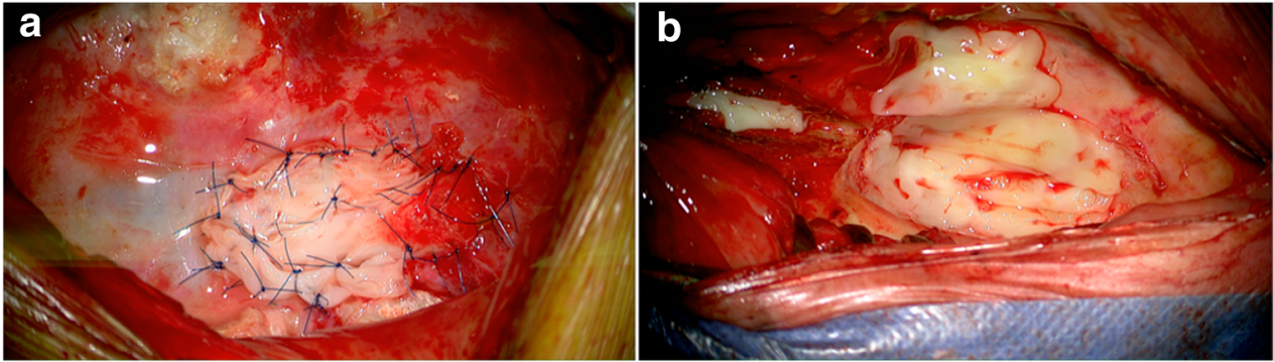

Outcome assessed at 6 weeks was disappointing in the first patient. Although the immediate postoperative course was uneventful with a total resolution of symptoms, after 1 week, the patient complained of recurrent symptoms. The second patient's symptoms were improved at 6 weeks follow-up.

\section{Discussion}

This pilot study discusses possible applications of L-PRF in neurosurgery and explores the safety of L-PRF in cranial and spinal surgery. Preliminary results are promising with respect to applicability and safety, justifying further studies.

Although techniques and materials for dural closure have substantially improved over the past decades, neurosurgeons are still facing problems related to chronic postoperative CSF leakage. L-PRF could be a novel potent ingredient for dural repair and has been successfully introduced in other specialties [16]. Major advantages reside in the fact that it is safe, completely autologous, and readily available. The use of LPRF is inexpensive since eight blood collection tubes cost about 10 USD, which compares very favorably to commercial fibrin glues. Since L-PRF contains specific growth factors and has immunological and antibacterial properties, theoretical advantages could include improved wound healing as well as reduced infection risks [12].

In this study, L-PRF served for dural reinforcement and repair in cranial skull base as well as spinal surgery. L-PRF was used to plug defects in endoscopic transsphenoidal surgery and was used as onlay grafts to enhance dural closure. The good tensile strength of the L-PRF membranes allows to withstand mechanical forces (e.g., expansion, compression) and allows for suturing the membrane into a dural defect. One of the downsides is the relatively small size of a single L-PRF membrane, which makes large dural defects less attractive for this procedure although multiple membranes can be sutured together. No perioperative or short-term postoperative complications related to the use of L-PRF were recorded in this series.

CSF leakage is also of concern after spinal surgery with an occurrence of $3-10 \%$ in primary surgery $[4,15]$ and twice these numbers in revision surgery [21]. Different treatment strategies have been described including autologous grafts (e.g., muscle, fat), xenografts (bovine pericardium), collagen substitutes, and fibrin glues [14, 15]. An alternative approach consists of the introduction of L-PRF to aid in dural reconstruction, which was used in two patients after several attempts to repair a chronic CFS leak after spine surgery.

In $6 \%$ of cases, the preparation of L-PRF failed as no clot formation was present. We attributed this failure to the prolonged time interval between the filling of the blood collection tubes and centrifugation. A critical interval of $60 \mathrm{~s}$ has been reported in the literature [12].

\section{Limitations}

One of the major limitations of the study involves the relatively small group size and the absence of long-term follow-up data, including postoperative imaging. In this study, L-PRF was often used in combination with classical sealants, and therefore, results cannot be uniquely attributed to the use of L-PRF. Moreover, we did not study the use of L-PRF in regular supratentorial surgeries and only included skull base and posterior fossa surgeries since these surgeries tend to have a higher propensity for leakage. In future applications, we intend to compare the use of L-PRF with commercial fibrin glue in a randomized controlled study in skull base, posterior fossa, and supratentorial surgery.

\section{Future directions}

Whether L-PRF will be an alternative to commercial fibrin sealants and/or could serve as an adjunct to classic dural closure will be the topic of future randomized trials.

A different application could include peripheral nerve surgery [23] where fibrin glues are currently used for suturing and where L-PRF could serve as an adhesive and could create a micro-environment of growth factors promoting nerve repair [19]. Since L-PRF can also serve as a carrier for bone graft, another theoretical application could involve the use of L-PRF in the reconstruction of skull defects and in spinal fusion surgery $[8,16]$.

At present, tissue reactions to L-PRF in the cranium and spinal canal have not been systematically studied. Postoperative imaging data, in particular MRI, are definitely needed to evaluate the interactions of L-PRF with surrounding tissues. 


\section{Conclusion}

The application of L-PRF in neurosurgery is feasible with the major advantage being the safety profile (no risk of disease transmission, no allergic reactions, no wound healing problems). L-PRF can be used for the reconstruction of small- to medium-sized dural defects and can also serve as an adhesive for dural reinforcement. L-PRF is inexpensive, autologous, and readily available, its application easy and straightforward. Since L-PRF is blood-derived, no donor-site morbidity is present. Whether this poor man's solution to dural repair will offer long-term applications in neurosurgery will be subject to future randomized studies.

\section{Compliance with ethical standards}

Conflict of interest All authors certify that they have no affiliations with or involvement in any organization or entity with any financial interest (such as honoraria; educational grants; participation in speakers' bureaus; membership, employment, consultancies, stock ownership, or other equity interest; and expert testimony or patent-licensing arrangements), or non-financial interest (such as personal or professional relationships, affiliations, knowledge or beliefs) in the subject matter or materials discussed in this manuscript.

Ethical approval All procedures performed in studies involving human participants were in accordance with the ethical standards of the institutional and/or national research committee (name of institute/committee) and with the 1964 Helsinki declaration and its later amendments or comparable ethical standards.

Informed consent For this type of study formal consent is not required. Additional informed consent was obtained from all individual participants for whom identifying information is included in this article.

\section{References}

1. Assad M, Bitar W, Alhajj MN (2017) Closure of oroantral communication using platelet-rich fibrin: a report of two cases. Ann Maxillofac Surg 7:117-119. https://doi.org/10.4103/ams.ams_77_17

2. Bajaj P, Pradeep AR, Agarwal E, Rao NS, Naik SB, Priyanka N, Kalra N (2013) Comparative evaluation of autologous platelet-rich fibrin and platelet-rich plasma in the treatment of mandibular degree II furcation defects: a randomized controlled clinical trial. J Periodontal Res 48:573-581. https://doi.org/10.1111/jre.12040

3. Bill TJ, Foresman PA, Rodeheaver GT, Drake DB (2001) Fibrin sealant: a novel method of fixation for an implantable ultrasonic microDoppler probe. J Reconstr Microsurg 17:257-262. https://doi. org/10.1055/s-2001-14517

4. Cammisa FP Jr, Girardi FP, Sangani PK, Parvataneni HK, Cadag S, Sandhu HS (2000) Incidental durotomy in spine surgery. Spine (Phila Pa 1976) 25:2663-2667

5. Caroli E, Rocchi G, Salvati M, Delfini R (2004) Duraplasty: our current experience. Surg Neurol 61:55-59 discussion 59

6. Castro AB, Meschi N, Temmerman A, Pinto N, Lambrechts P, Teughels W, Quirynen M (2017) Regenerative potential of leucocyte- and platelet-rich fibrin. Part A: intra-bony defects, furcation defects and periodontal plastic surgery. A systematic review and meta-analysis. J Clin Periodontol 44:67-82. https://doi.org/10. $1111 /$ jcpe. 12643

7. Castro AB, Meschi N, Temmerman A, Pinto N, Lambrechts P, Teughels W, Quirynen M (2017) Regenerative potential of leucocyte- and platelet-rich fibrin. Part B: sinus floor elevation, alveolar ridge preservation and implant therapy. A systematic review. J Clin Periodontol 44:225-234. https://doi.org/10.1111/jepe.12658

8. Cortellini S, Castro AB, Temmerman A, Vandessel J, Pinto N, Jacobs R, Quirynen M (2018) L-PRF block for bone augmentation procedure: a proof-of-concept study. J Clin Periodontol. https://doi. org $/ 10.1111 /$ jcpe. 12877

9. Cronkite EP, Lozner EL, Deaver JM (1944) Use of thrombin and fibrinogen in skin grafting. JAMA 124:976-978

10. Ding H, Yuan JQ, Zhou JH, Zheng XY, Ye P, Mao C, Chen Q (2013) Systematic review and meta-analysis of application of fibrin sealant after liver resection. Curr Med Res Opin 29:387-394. https://doi.org/10.1185/03007995.2013.768216

11. Dohan Ehrenfest DM, Del Corso M, Diss A, Mouhyi J, Charrier JB (2010) Three-dimensional architecture and cell composition of a Choukroun's platelet-rich fibrin clot and membrane. J Periodontol 81:546-555. https://doi.org/10.1902/jop.2009.090531

12. Dohan Ehrenfest DM, Pinto NR, Pereda A, Jimenez P, Corso MD, Kang BS, Nally M, Lanata N, Wang HL, Quirynen M (2017) The impact of the centrifuge characteristics and centrifugation protocols on the cells, growth factors, and fibrin architecture of a leukocyteand platelet-rich fibrin (L-PRF) clot and membrane. Platelets:1-14. https://doi.org/10.1080/09537104.2017.1293812

13. Drake DB, Ferguson RE Jr (2001) Fibrin sealants in microvascular surgery: current status. J Long-Term Eff Med Implants 11:65-72

14. Epstein NE (2010) Dural repair with four spinal sealants: focused review of the manufacturers' inserts and the current literature. Spine J 10:1065-1068. https://doi.org/10.1016/j.spinee.2010.09.017

15. Epstein NE (2013) A review article on the diagnosis and treatment of cerebrospinal fluid fistulas and dural tears occurring during spinal surgery. Surg Neurol Int 4:S301-S317. https://doi.org/10.4103/ 2152-7806.111427

16. Fredes F, Pinto J, Pinto N, Rojas P, Prevedello DM, Carrau RL, Schmidt T (2017) Potential effect of leukocyte-platelet-rich fibrin in bone healing of Skull Base: a pilot study. Int J Otolaryngol 2017: 1231870. https://doi.org/10.1155/2017/1231870

17. Grey E (1915) Fibrin as haemostasis in cerebral surgery. Surg Gynecol Obstet 21:452-454

18. Houston KA, Rotstein OD (1988) Fibrin sealant in high-risk colonic anastomoses. Arch Surg 123:230-234

19. Huang Y, Bornstein MM, Lambrichts I, Yu HY, Politis C, Jacobs R (2017) Platelet-rich plasma for regeneration of neural feedback pathways around dental implants: a concise review and outlook on future possibilities. Int J Oral Sci 9:1-9. https://doi.org/10. 1038/ijos.2017.1

20. Ito K, Yamada Y, Naiki T, Ueda M (2006) Simultaneous implant placement and bone regeneration around dental implants using tissue-engineered bone with fibrin glue, mesenchymal stem cells and platelet-rich plasma. Clin Oral Implants Res 17:579-586. https://doi.org/10.1111/j.1600-0501.2006.01246.x

21. Khan MH, Rihn J, Steele G, Davis R, Donaldson WF 3rd, Kang JD, Lee JY (2006) Postoperative management protocol for incidental dural tears during degenerative lumbar spine surgery: a review of 3 , 183 consecutive degenerative lumbar cases. Spine (Phila Pa 1976) 31:2609-2613. https://doi.org/10.1097/01.brs.0000241066.55849.41

22. Loose HW, Haslam PJ (1998) The management of peripheral arterial aneurysms using percutaneous injection of fibrin adhesive. $\mathrm{Br} \mathrm{J}$ Radiol 71:1255-1259. https://doi.org/10.1259/bjr.71.852.10318997

23. Matras H, Dinges HP, Lassmann H, Mamoli B (1972) Suture-free interfascicular nerve transplantation in animal experiments. Wien Med Wochenschr 122:517-523 
24. Naik AR, Ramesh AV, Dwarkanath CD, Naik MS, Chinnappa $A B$ (2013) Use of autologous platelet rich plasma to treat gingival recession in esthetic periodontal surgery. J Indian Soc Periodontol 17:345-353. https://doi.org/10.4103/0972124X.115665

25. Naik B, Karunakar P, Jayadev M, Marshal VR (2013) Role of platelet rich fibrin in wound healing: a critical review. J Conserv Dent 16:284-293. https://doi.org/10.4103/0972-0707.114344

26. Narakas A (1988) The use of fibrin glue in repair of peripheral nerves. Orthop Clin North Am 19:187-199

27. Orci LA, Oldani G, Berney T, Andres A, Mentha G, Morel P, Toso C (2014) Systematic review and meta-analysis of fibrin sealants for patients undergoing pancreatic resection. HPB (Oxford) 16:3-11. https://doi.org/10.1111/hpb.12064
28. Shaffrey CI, Spotnitz WD, Shaffrey ME, Jane JA (1990) Neurosurgical applications of fibrin glue: augmentation of dural closure in 134 patients. Neurosurgery 26:207-210

29. Simon D, Manuel S, Geetha V, Naik BR (2004) Potential for osseous regeneration of platelet-rich plasma - a comparative study in mandibular third molar sockets. Indian J Dent Res 15:133-136

30. Soldatova L, Campbell RG, Elkhatib AH, Schmidt TW, Pinto NR, Pinto JM, Prevedello DM, Ditzel Filho LF, Otto BA, Carrau RL (2017) Role of leukocyte-platelet-rich fibrin in endoscopic endonasal skull base surgery defect reconstruction. J Neurol Surg B Skull Base 78:59-62. https://doi.org/10.1055/s-0036-1584894

31. Wolner E (1982) Fibrin gluing in cardiovascular surgery. Thorac Cardiovasc Surg 30:236-237. https://doi.org/10.1055/s-20071022396 